\title{
Biocatalytic Production of Glucosamine from N-Acetylglucosamine by Diacetylchitobiose Deacetylase ${ }^{\mathbb{S}}$
}

\author{
Zhu Jiang ${ }^{1}$, Xueqin $\mathrm{Lv}^{1,2}$, Yanfeng Liu ${ }^{1,2}$, Hyun-dong Shin ${ }^{3}$, Jianghua $\mathrm{Li}^{2}$, Guocheng $\mathrm{Du}^{1,2}$, and Long Liu ${ }^{1,2 *}$ \\ ${ }^{1}$ Key Laboratory of Carbohydrate Chemistry and Biotechnology, Ministry of Education, Jiangnan University, Wuxi 214122, P.R. China \\ ${ }^{2}$ Key Laboratory of Industrial Biotechnology, Ministry of Education, Jiangnan University, Wuxi 214122, P.R. China \\ ${ }^{3}$ School of Chemical and Biomolecular Engineering, Georgia Institute of Technology, Atlanta GA 30332, USA
}

\author{
Received: May 27, 2018 \\ Revised: July 3, 2018 \\ Accepted: July 18, 2018 \\ First published online \\ July 19, 2018 \\ *Corresponding author \\ Phone: +86-510-85918312; \\ Fax: +86-510-85918309; \\ E-mail: longliu@jiangnan.edu.cn \\ S upplementary data for this \\ paper are available on-line only at \\ http://jmb.or.kr. \\ pISSN 1017-7825, eISSN 1738-8872 \\ Copyright(C) 2018 by \\ The Korean Society for Microbiology \\ and Biotechnology
}

\begin{abstract}
Glucosamine $(\mathrm{GlcN})$ is widely used in the nutraceutical and pharmaceutical industries. Currently, GlcN is mainly produced by traditional multistep chemical synthesis and acid hydrolysis, which can cause severe environmental pollution, require a long prodution period but a lower yield. The aim of this work was to develop a whole-cell biocatalytic process for the environment-friendly synthesis of glucosamine (GlcN) from $\mathrm{N}$-acetylglucosamine (GlcNAc). We constructed a recombinant Escherichia coli and Bacillus subtilis strains as efficient whole-cell biocatalysts via expression of diacetylchitobiose deacetylase ( $\mathrm{Dac}_{\mathrm{ph}}$ ) from Pyrococcus furiosus. Although both strains were biocatalytically active, the performance of B. subtilis was better. To enhance GlcN production, optimal reaction conditions were found: B. subtilis whole-cell biocatalyst $18.6 \mathrm{~g} / 1$, temperature $40^{\circ} \mathrm{C}, \mathrm{pH} 7.5$, GlcNAc concentration $50 \mathrm{~g} / 1$ and reaction time $3 \mathrm{~h}$. Under the above conditions, the maximal titer of GlcN was $35.3 \mathrm{~g} / \mathrm{l}$, the molar conversion ratio was $86.8 \%$ in 3-L bioreactor. This paper shows an efficient biotransformation process for the biotechnological production of GlcN in B. subtilis that is more environmentally friendly than the traditional multistep chemical synthesis approach. The biocatalytic process described here has the advantage of less environmental pollution and thus has great potential for largescale production of GlcN in an environment-friendly manner.
\end{abstract}

Keywords: Whole-cellbiocatalyst, glucosamine, diacetylchitobiose, deacetylase, Bacillus subtilis

\section{Introduction}

Glucosamine (GlcN, 2-amino-2-deoxy-D-glucose) is an amino sugar obtained by substitution of a hydroxyl group in glucose with an amino group. GlcN has been widely used in food, cosmetics, and pharmaceutical industries, especially in osteoarthritis treatment [1, 2]. In humans, GlcN is a precursor of the disaccharide units of glycosaminoglycans (such as hyaluronic acid, chondroitin sulfate, and keratan sulfate), which are necessary to repair and maintain healthy cartilage and joint function $[3,4]$. Currently, GlcN is mainly produced by acid hydrolysis of chitin and chitosan extracted from crab and shrimp shells. On the other hand, this extraction method poses some problems such as severe environmental pollution and potential allergic reactions in consumers. Recently, a new microbial fermentation procedure for the production of GlcN and GlcNAc was developed. The strains used for GlcN and GlcNAc production include fungi, viz., Aspergillus sp. BCRC 31742 [5, 6], genetically modified Escherichia coli $[7,8]$, and genetically modified Bacillus subtilis [9]. For fermentation by means of filamentous fungi, the GlcN production from the fungal cell wall requires acid hydrolysis and a long culture period. Regarding the engineered E.coli and B. subtilis, these methods have a high yield of GlcNAc but a lower yield of GlcN. As reported [7, 8], the production of GlcN requires acid hydrolysis; therefore, it also entails serious pollution. The low productivity and drawbacks of these approaches weaken their economic competitiveness. Besides, chitin could be hydrolyzed by chitinase to monomeric GlcNAc. As a result, some productive methods have been proposed for obtaining monomeric GlcNAc, but 


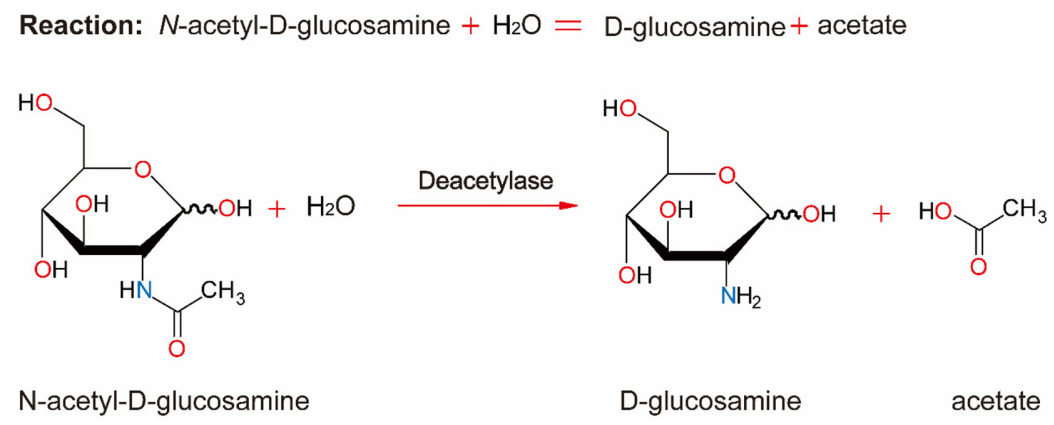

Fig. 1. The deacetylation reaction of diacetylchitobiose deacetylase $\left(\mathrm{Dac}_{\mathrm{ph}}\right)$ from P. horikoshii.

there isno high-efficiency method for the production of GlcN. Therefore, to solve the above problems, much attention has been given to manufacturing GlcN by an environmentally friendly method and to the development of a biocatalytic process for the environment-friendly synthesis of GlcN from GlcNAc.

Deacetylase has been mentioned in the literature in this regard, but has some disadvantages, such as poor stability, low tolerance of its substrate, low activity, and a low yield. A novel pathway of chitin degradation in Pyrococcus furiosus has been reported [10, 11]. In Archaea, the diacetylchitobiose deacetylase plays an important role in the unique chitin degradation pathway. The enzyme in question, diacetylchitobiose deacetylase, can remove the $\mathrm{N}$-acetyl group of the GlcNAc, yielding GlcN. It can also work in combination with glucosaminidase to hydrolyze diacetylchitobiose to GlcN [12]. For this reason, it is called diacetylchitobiose deacetylase $\left(\mathrm{Dac}_{\mathrm{ph}}\right)$. It can hydrolyze monomeric $\mathrm{N}$-acetylglucosamine efficiently. The deacetylase reaction (Fig. 1) showed the elements in the catalyst process, as well as the changes of chemical structures between GlcNAc and GlcN. The $D a c_{p h}$ gene is $819 \mathrm{bp}$ long and encodes a 273 -amino acid protein, and theoretical molecular mass of $\mathrm{Dac}_{\mathrm{ph}}$ is estimated to be $31.6 \mathrm{kDa}$ on the web site http://web.expasy.org/compute $\mathrm{pi} /$. The recombinant $\mathrm{Dac}_{\mathrm{ph}}$ is tolerant to heat treatment at $85^{\circ} \mathrm{C}$ for $30 \mathrm{~min}$. This phenomenon is consistent with previous reports; it is derived from hyperthermophilic archaea, and may also be useful for stable biotransformation [13].

In the present study, we expressed diacetylchitobiose deacetylase from P. horikoshii $\left(\mathrm{Dac}_{\mathrm{ph}}\right)$ in E. coli BL21(DE3) and B. subtilis WB600 to produce GlcN in one step from GlcNAc using the E. coli and B. subtilis strains engineered for whole-cell biocatalysis. The engineered strains were tested as whole-cell catalysts for deacetylation of GlcNAc to GlcN. As compared with E. coli, the expression of $\mathrm{Dac}_{\mathrm{ph}}$ and the whole-cell biocatalytic activity of the B. subtilis were higher. In addition, B. subtilis is the best-characterized gram-positive bacterium and has unique advantages as a host for large-scale industrial production of enzymes [11, $14,15]$, such as bacteriophage resistance factors and has the generally recognized as safe (GRAS) status granted by the United States Food and Drug Administration [16-19]. Therefore, we selected B. subtilis for further experiments. Finally, the reaction conditions of the proposed bioconversion were optimized, leading to enhanced production of GlcN from GlcNAc.

\section{Materials and Methods}

\section{Materials, Plasmids, and Strains}

Bacterial strains, plasmids, and primers used in this study are listed in Table 1. E. coli JM109 was employed for cloning and construction of genes and plasmids. E. coli BL21(DE3) and B. subtilis WB600 served as the biocatalytic hosts. Plasmid pP43NMK was a generous gift from Dr. Zhang (Department of Biological Systems Engineering, Virginia Tech, USA) [20]. The SanPrep Column Plasmid Mini-Preps Kit and ClonExpress MultiS One Step Cloning Kit were purchased from Sangon (China), whereas the DNA purification kit and restriction enzymes from Takara (China). The standard sample of GlcN was acquired from Sigma-Aldrich (USA), whereas ampicillin came from Amresco (USA) and isopropyl- $\beta$-D1-thiogalactopyranoside (IPTG) came from Merck (Germany). All other chemicals were purchased from Shanghai Sangon Biological Engineering Technology and Services Co., Ltd. (China). Primer synthesis and DNA sequencing were performed by Shanghai Sangon Biological Engineering Technology and Services Co., Ltd. E. coli and B. subtilis seed cultures were initiated in the LuriaBertani (LB) medium (LB: $10 \mathrm{~g} / 1$ tryptone, $5 \mathrm{~g} / 1$ yeast extract, and $10 \mathrm{~g} / 1 \mathrm{NaCl})$, and the growth of whole-cell biocatalysts were incubated in Terrific Broth (TB) (TB: $12 \mathrm{~g} / 1$ tryptone, $24 \mathrm{~g} / 1$ yeast extract, $4 \mathrm{ml} / 1$ glycerol, $2.31 \mathrm{~g} / 1 \mathrm{KH}_{2} \mathrm{PO}_{4}$, and $12.54 \mathrm{~g} / 1 \mathrm{~K}_{2} \mathrm{HPO}_{4}$ ) with the same antibiotic.

Recombinant-Plasmid Construction and Bacterial Transformation

The genes encoding $\mathrm{Dac}_{\mathrm{ph}}$ (PH0499) were synthesized by Sangon Biotech Co., Ltd. (China) and were optimized for 
Table 1. Strains, plasmids, and primers used in this study.

\begin{tabular}{|c|c|c|}
\hline Strain, plasmid or primer & Description or sequence $\left(5^{\prime}-3^{\prime}\right)$ & Source \\
\hline \multicolumn{3}{|l|}{ Strains } \\
\hline E. coli JM109 & Cloning strain & Takara, Ostu, Japan \\
\hline E. coli BL21(DE3) & Expression strain & Invitrogen,Carlsbad, CA \\
\hline B. subtilis WB600 & Expression strain & Lab stock \\
\hline E. coli-Dac & E. coli BL21(DE3) containing a pET-28a-Dac & This work \\
\hline B. subtilis-Dac & B. subtilis WB600 containing a pP43NMK-Dac & This work \\
\hline \multicolumn{3}{|l|}{ Plasmids } \\
\hline pET-28a $(+)$ & $\operatorname{Kan}^{\mathrm{r}}$ & Invitrogen, Carlsbad, CA \\
\hline pP43NMK & $\operatorname{Kan}^{r} ; \mathrm{Amp}^{\mathrm{r}}$ & Virginia Tech, USA \\
\hline pET-28a-Dac & pET-28a $(+)$ containing Dac & This work \\
\hline pP43NMK-Dac & pP43NMK containing Dac & This work \\
\hline \multicolumn{3}{|l|}{ Primers } \\
\hline $\mathrm{Dac}_{\mathrm{ph}}-\mathrm{F} 1$ & \multicolumn{2}{|c|}{ GTGGACAGCAAATGGGTCGCGGATCCATGGTAGTGAACATGTTCGAAG } \\
\hline $\mathrm{Dac}_{\mathrm{ph}}-\mathrm{R} 1$ & \multicolumn{2}{|c|}{ CAGTGGTGGTGGTGGTGGTGCTCGAGGATAAGGTCAGTAAACGGTGT } \\
\hline $\mathrm{Dac}_{\mathrm{ph}}-\mathrm{F} 2$ & \multicolumn{2}{|c|}{ GTAAAATATAAAGTGATAGCGGTACCATTATAGGTAAGAGAGGAAT } \\
\hline $\mathrm{Dac}_{\mathrm{ph}}-\mathrm{R} 2$ & \multicolumn{2}{|c|}{ ACCATGATTACGCCAAGCTTCTGCAGTCAGATCAGGTCCGTAAACG } \\
\hline
\end{tabular}

Amp ${ }^{\mathrm{r}}$, ampicillin resistance; $\mathrm{Kan}^{\mathrm{r}}$, kanamycin resistance.

Italic letters represent the restriction enzyme sites, and underlined letters represent homologous sequences for cloning.

expression in E. coli and B. subtilis, respectively (Fig. S1). For expression in E. coli, plasmid pET-28a(+) was digested with BamHI and $\mathrm{XhoI}$ and then subjected to column purification. The $D a c_{p h}-E$ gene was amplified by PCR with gene-specific primers: $\mathrm{Dac}_{\mathrm{ph}}-\mathrm{F} 1$ and $\mathrm{Dac}_{\mathrm{ph}}-\mathrm{R} 1$. The PCR product was processed by gel purification and ligated into the pET-28a(+) vector with the clon Express One Step Cloning Kit (Vazyme Biotech Co., Ltd., China), yielding plasmid pET-28a-Dac. The recombinant plasmid was transformed into the host strain E. coli BL21(DE3) to obtain the engineered strain E. coli-Dac. Plasmid pET-28a(+) without the insert was transformed into E. coli BL21(DE3) cells as a control.

For expression in B. subtilis, plasmid pP43NMK was digested with KpnI and PstI and subjected to column purification. The $D a c_{p h}-B$ gene was amplified by PCR with gene-specific primers: $\mathrm{Dac}_{\mathrm{ph}}-\mathrm{F} 2$ and $\mathrm{Dac}_{\mathrm{ph}}-\mathrm{R} 2$. The amplicon was processed by gel purification and ligated into the pP43NMK vector by the same recombination method as described above, thereby yielding recombinant plasmid pP43NMK-Dac. The recombinant plasmid was transformed into host strain B. subtilis WB600 to obtain engineered strain B. subtilis-Dac. Plasmid PP43NMK without the insert was transformed into B. subtilis WB600 as the control. All the constructs were confirmed by restriction analysis and DNA sequencing. E. coli transformation was performed as described by Sambrook and Russell (2001), and B. subtilis transformation was carried out according to the manufacturer's protocol (MoBiTec).

\section{Biocatalyst Preparation}

The engineered E. coli and B. subtilis strains were inoculated into the LB medium containing kanamycin at a final concentration of 50 and $25 \mathrm{mg} / \mathrm{l}$, respectively. The bacteria were cultivated at $37^{\circ} \mathrm{C}$ overnight on a rotary shaker $(220 \mathrm{rpm})$ to prepare the seed cultures. For preparation of a biocatalyst from E. coli, $2 \%$ of the seed culture was then inoculated into the fermentation medium(TB) containing $50 \mathrm{mg} / 1$ kanamycin and was cultivated at $37^{\circ} \mathrm{C}$ with shaking at $220 \mathrm{rpm}$. When optical density at $600 \mathrm{~nm}\left(\mathrm{OD}_{600}\right)$ reached 0.5 , which was found to be the optimal time point for Dac $_{\mathrm{ph}}$ induction in pilot experiments, IPTG was immediately added to the broth to a final concentration of $0.05 \mathrm{mM}$ [21]. Next, the bacteria were cultivated at $37^{\circ} \mathrm{C}$ with shaking at $220 \mathrm{rpm}$ for $5 \mathrm{~h}$. For preparation of a biocatalyst from B. subtilis, $2 \%$ of the seed culture was inoculated into the fermentation medium(TB) supplemented with $25 \mathrm{mg} / 1$ kanamycin and was cultivated at $37^{\circ} \mathrm{C}$ and $220 \mathrm{rpm}$ for $18 \mathrm{~h}$ without any inducer. After that, the cells were harvested by centrifugation at $8,000 \times g$ for $10 \mathrm{~min}$ at $4^{\circ} \mathrm{C}$ and washed twice with sterilized water. After that, the cell pellet was resuspended in $50 \mathrm{mM}$ sodium phosphate buffer ( $\mathrm{pH}$ 7.5) and kept at $4^{\circ} \mathrm{C}$ for the subsequent biotransformation analysis and further experiments.

\section{Cell Density and Biocatalytic Assays}

$\mathrm{OD}_{600}$ was measured every $2 \mathrm{~h}$ in the growth culture until the stationary phase to construct the growth curve. $\mathrm{OD}_{600}$ was determined on a UVmini-1240 spectrophotometer (Shimadzu, Japan) and was converted to dry cell weight (DCW) according to the following equation: $\mathrm{DCW}(\mathrm{g} / \mathrm{l})=\left(0.4442 \times \mathrm{OD}_{600}\right)-0.021$.

Next, the reaction rate was determined in a whole-cell 
biocatalytic reaction. Namely, $50 \mathrm{~g} / 1$ GlcNAc and $18.6 \mathrm{~g} / 1$ wholecell biocatalyst were mixed in $50 \mathrm{mM}$ sodium phosphate buffer (pH 7.5). The reaction proceeded in a 250-ml shaking flask and incubated on a rotary shaker at $30^{\circ} \mathrm{C}$ for $0.5 \mathrm{~h}$. To determine the conversion ratio of GlcNActo GlcN, different concentrations of GlcNAc were added into the sodium phosphate buffer containing $18.6 \mathrm{~g} / \mathrm{l}$ cells. The reaction was carried out in $250-\mathrm{ml}$ shaking flasks and incubated on a rotary shaker at $30-90^{\circ} \mathrm{C}$ and pH 5.0-9.0 for $0.5-10 \mathrm{~h}$. The reaction was stopped by adding $\mathrm{HCl}$ to the system to a final concentration of $0.1 \mathrm{M}$, then centrifuged at $8,000 \times g$ for $10 \mathrm{~min}$. The supernatant was recovered for the quantification of GlcNAc and GlcN by HPLC, as described below.

\section{Optimization of $\mathrm{pH}$, Cell Density, Substrate Concentration, and Temperature}

For optimization of all the variables, the reaction was conducted in 250-ml shaking flasks containing $20 \mathrm{ml}$ of the reaction mixture and incubated on a rotary shaker for $0.5 \mathrm{~h}$. For $\mathrm{pH}$ optimization, the reaction was conducted at $30^{\circ} \mathrm{C}$ in sodium phosphate buffer ( $\mathrm{pH}$ 5.0-9.0) containing $50 \mathrm{~g} / \mathrm{l} \mathrm{GlcNAc.} \mathrm{For} \mathrm{DCW} \mathrm{optimization,}$ the conditions were $50 \mathrm{~g} / 1 \mathrm{GlcNAc}, 30^{\circ} \mathrm{C}$, and $\mathrm{pH} 7.5$. To optimize the substrate concentration, the reaction was conducted at $\mathrm{pH} 7.5$, $30^{\circ} \mathrm{C}$, with the GlcNAc concentration ranging from 10 to $80 \mathrm{~g} / \mathrm{l}$. For temperature optimization, the reaction was carried out at $\mathrm{pH} 7.5$, with temperatures varying between $30^{\circ} \mathrm{C}$ and $90^{\circ} \mathrm{C}$. To optimize the catalytic time, the reaction was carried out at different temperatures $\left(30-90^{\circ} \mathrm{C}\right)$ and $\mathrm{pH} 7.5$ for $0.5-5 \mathrm{~h}$. The resulting samples were centrifuged, and the supernatant was tested by HPLC.

\section{Production of GlcN in 3-L Bioreactor}

The production of GlcN was performed in 3-L bioreactor (BioFlo 115, New Brunswick Scientific Co., USA) using a 1.4-L reaction mixture. Reactions were performed using the standard whole-cell biocatalytic and the conditions based on the optimal conditions in shaking flask, as described above. Agitation was provided by 26 -bladed disk turbines. The $\mathrm{pH}$ was automatically kept at 7.5 via the addition of $5 \mathrm{M} \mathrm{NaOH}$, and the temperature was maintained at $40^{\circ} \mathrm{C}$. The aeration rate and agitation speed were $1.5 \mathrm{vvm}$ and $300 \mathrm{rpm}$, respectively.

\section{The Stability of GlcN and GlcNAc under the Conversion Conditions}

The determination of GlcN and GlcNAc stability is carried out under the optimal conversion conditions. The conditions were $40^{\circ} \mathrm{C}$, pH 7.5 (50 mM sodium phosphate buffer) and $50 \mathrm{~g} / 1$ GLcNAc for incubating $0-5 \mathrm{~h}$ without cells. As for the stability of $\mathrm{GlcN}$, the experiments were performed at $40^{\circ} \mathrm{C}, \mathrm{pH} 7.5(50 \mathrm{mM}$ sodium phosphate buffer) and $50 \mathrm{~g} / \mathrm{l} \mathrm{GLcN}$ for $0-5 \mathrm{~h}$ without cells. The concentration of GlcN and GlcNAc were measured every $1 \mathrm{~h}$ to construct the stability curve were tested by HPLC.

\section{Analytical Methods}

GlcN were quantified by HPLC (Agilent1260 series, USA) on a Thermo ODS-2 HYPERSIL $C_{18}$ column $(250 \mathrm{~mm} \times 4.0 \mathrm{~mm}$, USA) by the ortho-phthalaldehyde (OPA) precolumnde rivatization method [22, 23]. The supernatant of each reaction system was passed through a membrane filter with $0.22-\mu \mathrm{m}$ pore size, and $10 \mu \mathrm{l}$ of the filtrate was injected into the HPLC column. The concentrations of GlcNAc and acetate in the supernatant were measured by HPLC on an instrument equipped with an HPX-87H column (Bio-Rad, USA) and a refractive index detector. HPLC was carried out with $5 \mathrm{mM} \mathrm{H}_{2} \mathrm{SO}_{4}$ as the mobile phase at a flow rate of $0.6 \mathrm{ml} / \mathrm{min}$ and $40^{\circ} \mathrm{C}$. Pure substances served as standards.

Sodium dodecyl sulfate-polyacrylamide gel electrophoresis (SDS-PAGE) was performed on a $10 \%$ running gel (Bio-Rad Laboratories, USA). The target proteins were released from the cells by sonication, then, samples were incubated in denaturing buffer at $10040^{\circ} \mathrm{C}$ for $10 \mathrm{~min}$. The prepared samples and marker were loaded into wells and separated by electrophoresis in MES SDS running buffer, and resolved proteins were visualized by staining with Coomassie Brilliant Blue G250.

Protein concentration was measured by Bradford method (Bradford 1976) using bovine serum albumin as the standard.

The biocatalyst activity was calculated according to the following equation:

$$
\text { Activity }=\mathrm{C}_{(\mathrm{GlcN})} /(\mathrm{DCW} \times \mathrm{T})
$$

where $\mathrm{C}_{(\mathrm{Glc}) \mathrm{N}}$ is the concentration ( $\left.\mathrm{g} / \mathrm{l}\right)$ of $\mathrm{GlcN}$ that was generated by the reaction, DCW is expressed in $\mathrm{g} / \mathrm{l}$, and $\mathrm{T}$ denotes reaction time (min).

The reaction rate is expressed as

$$
\text { Reaction rate }=\mathrm{C}_{(\mathrm{GlcN})} / \mathrm{T}
$$

where $\mathrm{C}_{(\mathrm{GlcN})}$ is the concentration $(\mathrm{g} / \mathrm{l})$ of $\mathrm{GlcN}$ that was generated by the reaction, and $\mathrm{T}$ represents reaction time (h).

The conversion yield is given by

Conversion ratio $(\%)=\left(\mathrm{M}_{2} / \mathrm{M}_{1}\right) \times 100$

where $\mathrm{M}_{1}$ is the amount (mmol) of GlcNAc before transformation, $\mathrm{M}_{2}$ is the amount of GlcN that was generated by the reaction.

\section{Statistical Analysis}

All the experiments were conducted at least three times, and the results were expressed as mean \pm standard deviation $(n=3)$.

\section{Results and Discussion}

\section{Expression of Diacetylchitobiose Deacetylase in B. subtilis and $E$. coli}

The $D a c_{p h}$ gene (from $P$. horikoshii) after codon optimization was cloned into expression vectors pET-28a (+) and pP43NMK and sequenced, respectively (Fig. S1). The recombinant 
A

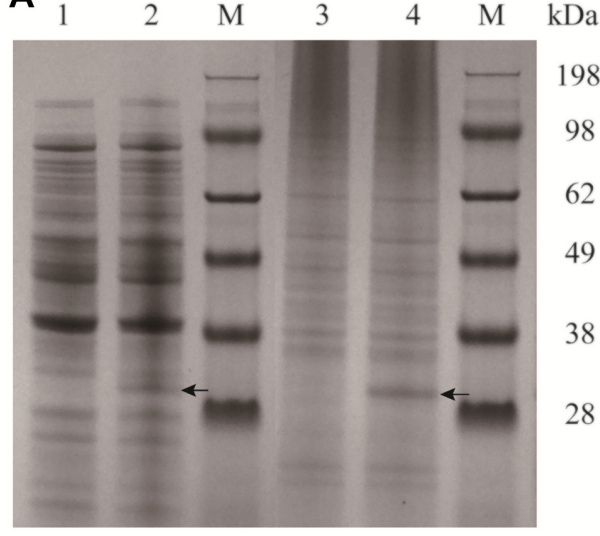

B

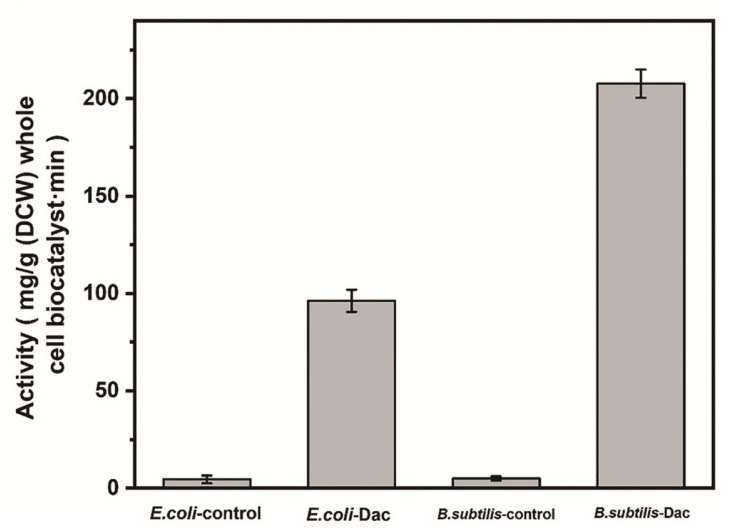

Fig. 2. SDS-PAGE and deacetylase activity analysis of recombinant strains.

(A) SDS-PAGE analysis of Dac $_{\mathrm{ph}}$ expression in the recombinant strains. M: protein marker, 1: E. coli-Control (harboring blank pET-28a (+)

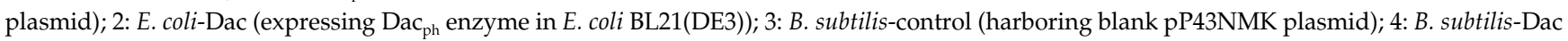
(expressing $\mathrm{Dac}_{\mathrm{ph}}$ enzyme in B. subtilis WB600). (B) Comparison of the whole-cell biocatalytic deacetylase activity of recombinant E.coli BL21(DE3) and B. subtilis WB600 expressing Dac $\mathrm{ph}_{\mathrm{ph}}$ enzyme. E. coli-Control, harboring blank pET-28a(+) plasmid; B. subtilis-control, harboring

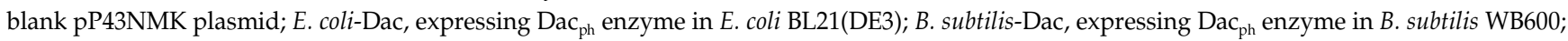
The data shown are mean values from triplicates with error bars indicating the standard deviation.

plasmids were next transformed into E. coli BL21(DE3) and B. subtilis WB600, respectively. The expression systems were under the control of the T7 promoter and p43 promoter, respectively. Dac $\mathrm{ph}_{\mathrm{ph}}$ was expressed successfully in both host strains (data not shown). The cells were harvested on stationary phase (as shown in Fig. S2). SDS-PAGE analysis showed that both recombinant strains expressed a $32-\mathrm{kDa}$ protein successfully. Obviously, B. subtilis-Dac ${ }_{\mathrm{ph}}$ had a thicker 32-kDa Dac $\mathrm{ph}_{\mathrm{ph}}$ band in the whole-cell fraction (Fig. 2A). $\mathrm{Dac}_{\mathrm{ph}}$ activity was measured in the whole-cell biocatalysts and in the cytosolic fraction. The recombinant $\mathrm{Dac}_{\mathrm{ph}}$ activity was 2.2-fold higher in the whole-cell preparation of B. subtilis in comparison with E. coli (Fig. 2B). On the basis of these results, we proceeded to the biochemical analysis of the whole-cell biocatalytic activity of recombinant-Dac $\mathrm{ph}^{-}$ expressing B. subtilis.

\section{The Influence of Dac ${ }_{\mathrm{ph}}$ Overexpression on Cell Growth}

Next, we determined whether the expression of $\mathrm{Dac}_{\mathrm{ph}}$ affects cell growth of E. coli and B. subtilis. The cell growth curves of E. coli and B. subtilis are shown in Fig. S2. Readers can see that the engineered $\mathrm{Dac}_{\mathrm{ph}}$-expressing strains grew faster than the control strains (not expressing $\mathrm{Dac}_{\mathrm{ph}}$ ), and the biomass values of the engineered strains were $\sim 2.1$-fold greater than those of the control. These data indicated that overexpressed $\mathrm{Dac}_{\mathrm{ph}}$ from P. horikoshii had positive effects on the strains under study in terms of cell growth. The reason for this phenomenon is not clear. Further studies are needed to explain this phenomenon.

\section{Effects of Key Variables on GlcN Production by the Whole-Cell Biocatalysts}

The enzymatic properties were evaluated to optimize the key variables of GlcN production by each whole-cell biocatalyst. The effects of $\mathrm{pH}$ on GlcN production were evaluated by analyzing the whole-cell biocatalyst reaction rate in $\mathrm{Na}_{2} \mathrm{HPO}_{4}-\mathrm{NaH}_{2} \mathrm{PO}_{4}$ buffers at $\mathrm{pH}$ levels ranging from 5.0 to 9.0 (Fig. 3A). The highest biocatalyst reaction rate $\left(17.9 \mathrm{~g} \cdot \mathrm{l}^{-1} \cdot \mathrm{h}^{-1}\right)$ was obtained when bioconversion was performed at $\mathrm{pH} 7.5$, generally in agreement with one report showing that the optimal $\mathrm{pH}$ for GlcNAc catalysis is 8.0 [13]. The effect of the biocatalyst concentration on biocatalyst reaction rate was evaluated next. The highest

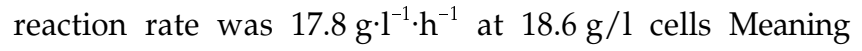
needs verification (Fig. 3B). To determine the optimal substrate concentration for bioconversion, the reactions were run at GlcNAc concentrations ranging from 10 to $80 \mathrm{~g} / \mathrm{l}$. The highest reaction rate was $18.9 \mathrm{~g} \cdot \mathrm{l}^{-1} \cdot \mathrm{h}^{-1}$ at $50 \mathrm{~g} / \mathrm{l}$ substrate (Fig. 3C). Fig. 3D shows the influence of reaction temperatures ranging from $30^{\circ} \mathrm{C}$ to $90^{\circ} \mathrm{C}$. The reaction rate increased with the increase of temperature. The highest reaction rate was $49.6 \mathrm{~g} \cdot \mathrm{l}^{-1} \cdot \mathrm{h}^{-1}$ at $80^{\circ} \mathrm{C}$. This finding is consistent with results of a report showing that $\mathrm{Dac}_{\mathrm{ph}}$ has excellent thermal stability, retaining activity at $85^{\circ} \mathrm{C}$ for 

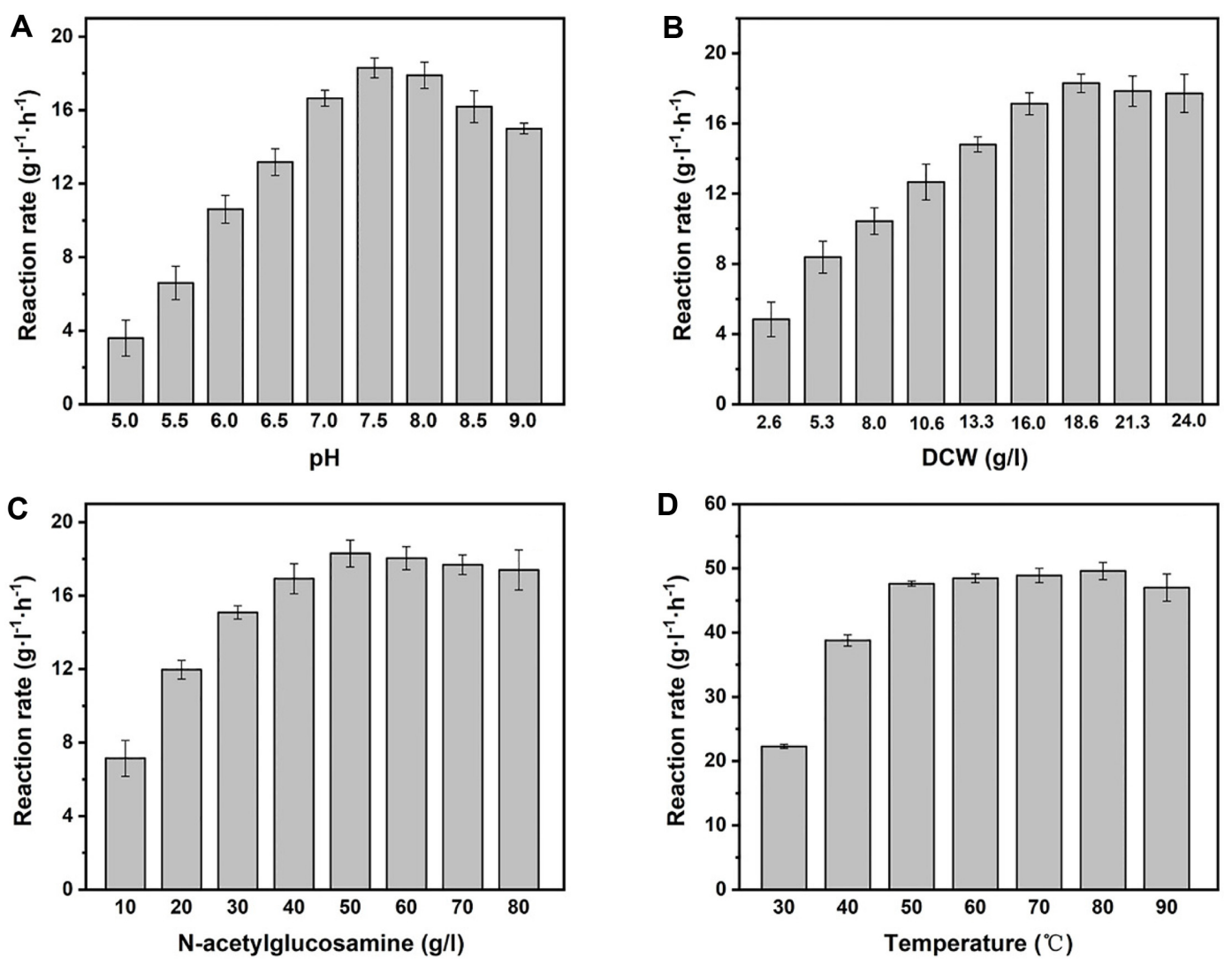

Fig. 3. The effect of $\mathrm{pH}, \mathrm{DCW}$, substrate and temperature on whole-cell biotransformation.

(A) The reaction was conducted at $30^{\circ} \mathrm{C}$ in sodium phosphate buffer ( $\left.\mathrm{pH} 5.0-9.0\right)$ containing $50 \mathrm{~g} / 1 \mathrm{GlcNAc}$. (B) The reaction was performed at the condition of $50 \mathrm{~g} / 1 \mathrm{GlcNAc}, 30^{\circ} \mathrm{C}$, and $\mathrm{pH}$ 7.5. (C) The reaction was conducted at $\mathrm{pH} 7.5,30^{\circ} \mathrm{C}$, with the GlcNAc concentrations ranging from 10 to $80 \mathrm{~g} / 1$. (D) The reaction was carried out at $\mathrm{pH} 7.5$, with temperatures varying between $30^{\circ} \mathrm{C}$ and $90^{\circ} \mathrm{C}$. Results were obtained with recombinant B. subtilis whole-cell biocatalyst. The data shown are mean values from triplicates with error bars indicating the standard deviation.

more than 30 min [21]. Product inhibition of $\mathrm{Dac}_{\mathrm{ph}}$ was assessed by measuring GlcN production. The biocatalyst reaction rate decreased sharply as GlcN concentration increased (Fig. S3).

The stability of GlcN was influenced by the temperature and $\mathrm{pH}$. According to one study, the degradation of GlcN increases with the increasing temperature and $\mathrm{pH}$ [8]. As shown in Fig. 3, we measured the GlcN concentration in the reaction system to construct the curve of yield of GlcN over time at different conversion temperatures (ranging from $30^{\circ} \mathrm{C}$ to $90^{\circ} \mathrm{C}$ ).

According to the Fig. 3D, the highest reaction rate was $49.6 \mathrm{~g} \cdot \mathrm{l}^{-1} \cdot \mathrm{h}^{-1}$ when the temperature was higher than $50^{\circ} \mathrm{C}$. But as shown in Fig. 4, the yield of GlcN decreased sharply at higher temperatures. Therefore, this bioconversion wasted a lot of GlcN when performed at a higher temperature. This phenomenon is reasonable. One possible explanation for the phenomenon is that the stability of GlcN was obviously influenced by the temperature at $\mathrm{pH} 7.5$; the degradation of $\mathrm{GlcN}$ increases with the increasing temperature. When the reaction was performed at a higher temperature, the production of GlcN occurs at a higher reaction rate. However, the GlcN, deacetyled from GlcNAc, was unstable in the current high temperature environment, and can be converted into other derivatives. As shown in Fig. 4, the yield of GlcN steadily increased when the reaction temperature was lower than $40^{\circ} \mathrm{C}$.

In addition, we measured the stability of substrate (GlcNAc) and product $(\mathrm{GlcN})$ under the optimal bioconversion conditions, the experiments were carried out with standard substrate and product in the reaction buffer solution (50 mM sodium phosphate buffer, $\mathrm{pH} 7.5$ ) without cells at $40^{\circ} \mathrm{C}$. According to the Fig. S4, the substrate (GlcNAc) was stable at the optimal bioconversion conditions. When the incubation time was $3 \mathrm{~h}$, the end of biocatalytic production of GlcN, the concentration of GlcNAc decreased from 50 to 


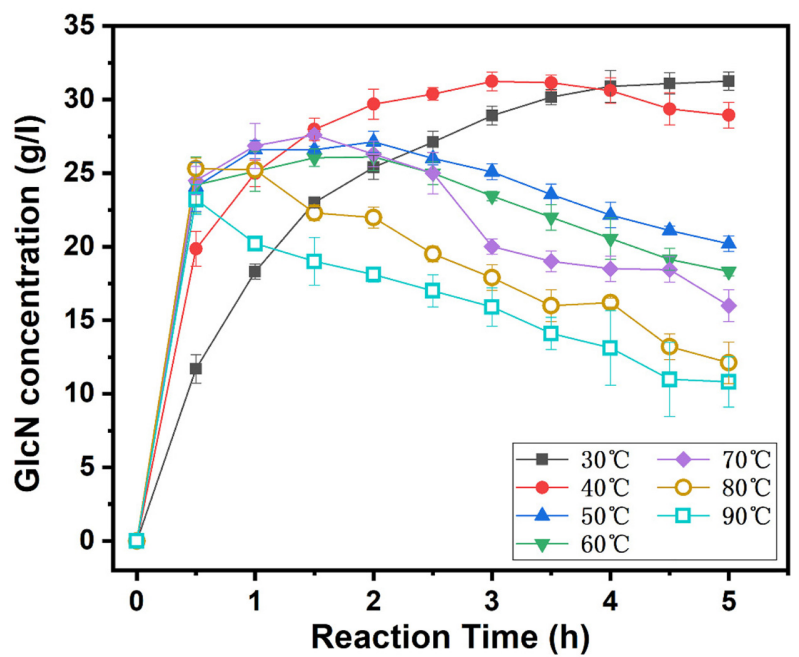

Fig. 4. Time profile of the GlcN production ( $\mathrm{g} / \mathrm{l})$ under different reaction temperatures $\left(30-90^{\circ} \mathrm{C}\right)$.

Symbol denotes: $\boldsymbol{\square}, 30^{\circ} \mathrm{C} ; \boldsymbol{\bullet}, 40^{\circ} \mathrm{C} ; \boldsymbol{\Delta}, 50^{\circ} \mathrm{C} ; \boldsymbol{\nabla}, 60^{\circ} \mathrm{C} ; \bullet, 70^{\circ} \mathrm{C} ; \bigcirc$, $80^{\circ} \mathrm{C} ; \square, 90^{\circ} \mathrm{C}$. Results were obtained with recombinant $B$. subtilis whole-cell biocatalyst. The reactions were conducted at $\mathrm{pH} 7.5$ in sodium phosphate buffer containing $50 \mathrm{~g} / \mathrm{l}$ GlcNAc and $18.6 \mathrm{~g} / \mathrm{l}$ cells. The data shown are mean values from triplicates with error bars indicating the standard deviation.

$49.3 \mathrm{~g} / 1$ and only $1.4 \%$ reduction. When the incubation time was extended to $5 \mathrm{~h}$, the concentration of GlcNAc was
$48.6 \mathrm{~g} / 1$ and decreased by $2.8 \%$. As shown in Fig. S4, under the optimal reaction conditions, the GlcN was relatively stable in the first $3 \mathrm{~h}$. The concentration of GlcN decreased from 50 to $48.1 \mathrm{~g} / 1$ and only $3.8 \%$ reduction. When the incubation time was extended, the concentration of GlcN decreased rapidly, the concentration of GlcN was $40.75 \mathrm{~g} / 1$ at $5 \mathrm{~h}$ and decreased by $18.9 \%$.

\section{Production of GlcN by the Whole-Cell Biocatalysts}

To use the whole-cell biocatalyst for GlcN production, the conversion ratio and the yield of GlcN were evaluated under different conditions. According to the above data, we obtained $30.2 \mathrm{~g} / 1 \mathrm{GlcN}$ when the reaction was performed at $40^{\circ} \mathrm{C}, \mathrm{pH} 7.5,18.6 \mathrm{~g} / 1$ cells, and $50 \mathrm{~g} / 1 \mathrm{GlcNAc}$ in $250-\mathrm{ml}$ shaking flask. In order to optimize the reaction time and determine the trend of $\mathrm{pH}$ in the catalytic system, bioconversion was evaluated in a shaking flask containing $18.6 \mathrm{~g} / 1$ cells and $50 \mathrm{~g} / 1 \mathrm{GlcNAc}$ at $40^{\circ} \mathrm{C}$ and $\mathrm{pH}$ 7.5. The highest yield of GlcN was obtained at $3 \mathrm{~h}$ and then decreased. The $\mathrm{pH}$ value in the catalytic system was gradually decreased from 7.5 to 6.3. For the conversion efficiency and economical industrial application, $3 \mathrm{~h}$ seems to be the ideal operation duration. Overall, the optimal conditions were $18.6 \mathrm{~g} / 1$ cells at $40^{\circ} \mathrm{C}$, pH 7.5 for $3 \mathrm{~h}$ (Fig. 5A).

To attain a higher titer of GlcN, amplification experiments of GlcN production were carried out in 3-L bioreactor
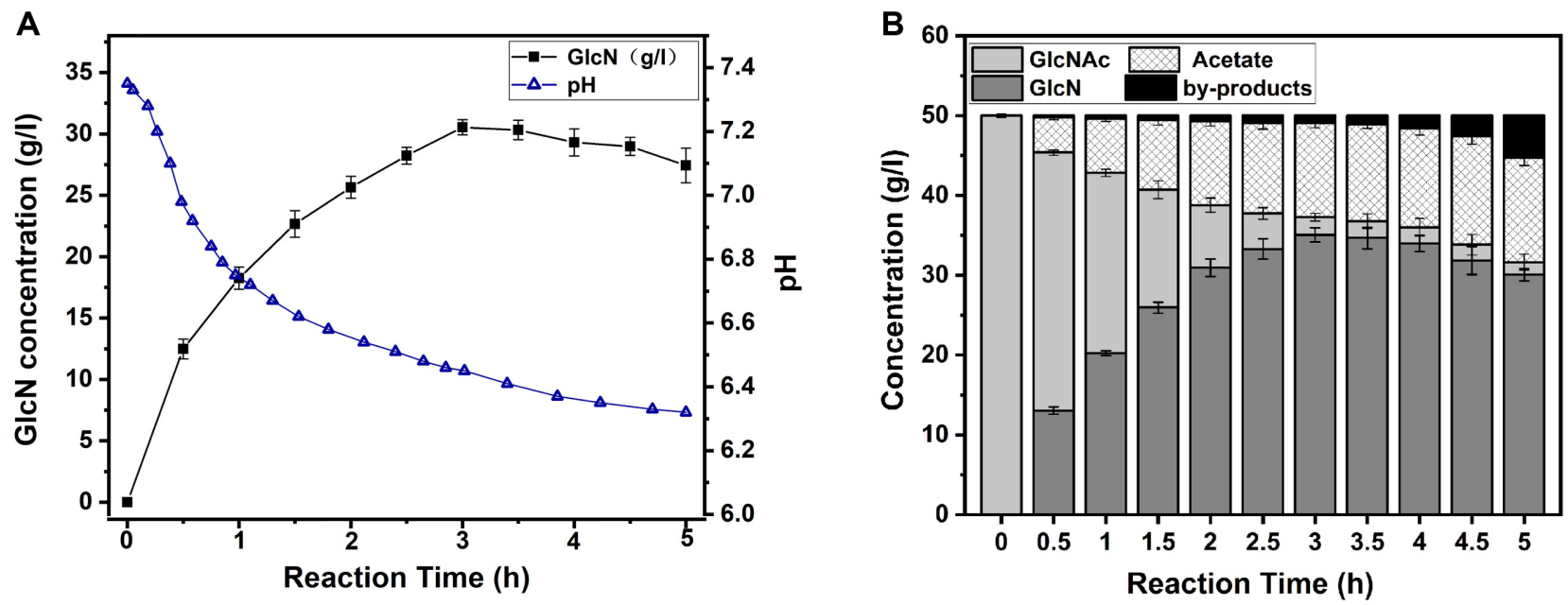

Fig. 5. Time profile of various parameters in different catalytic systems.

(A) Time course of GlcNproduction $(\boldsymbol{\square})$ and $\mathrm{pH}$ value $(\triangle)$ catalyzation in a 250-ml shaking flask. Results were obtained with recombinant B. subtilis whole-cell biocatalyst. The reaction was performed at $40^{\circ} \mathrm{C}$ in sodium phosphate buffer ( $\left.\mathrm{pH} 7.5\right)$ containing $50 \mathrm{~g} / 1 \mathrm{GlcNAc}$ and $18.6 \mathrm{~g} / 1$ cells. The data shown are mean values from triplicates with error bars indicating the standard deviation. (B) Time profile of various substances concentrations in the 3-L bioreactor catalytic system. The reaction was performed in 3-L bioreactor under the optimal conditions. The $\mathrm{pH}$ was automatically kept at 7.5 via the addition of $5 \mathrm{M} \mathrm{NaOH}$, and the temperature was maintained at $40^{\circ} \mathrm{C}$. Results were obtained with recombinant B. subtilis whole-cell biocatalyst. The data shown are mean values from triplicates with error bars indicating the standard deviation. 


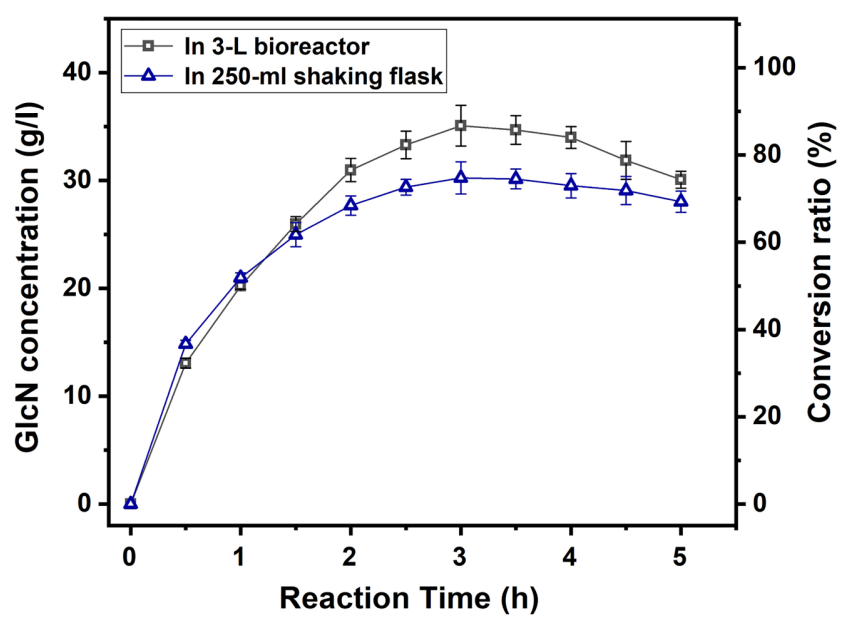

Fig. 6. Comparison of the GlcNproduction during the conversion between catalyzed in 3-L bioreactor $(\square)$ and 250-ml shaking flask $(\triangle)$.

Both reactions were performed under the optimal conditions, $40^{\circ} \mathrm{C}$, $\mathrm{pH} 7.5,18.6 \mathrm{~g} / 1$ cells and $50 \mathrm{~g} / 1$ GlcNAc. The data shown are mean values from triplicates with error bars indicating the standard deviation.

based on the optimal conditions in shaking flask. The concentration of various substances in the catalytic system varies with time were determined. The trend was generally consistent with shaking flask. The highest yield of GlcN $(35.3 \mathrm{~g} / \mathrm{l})$ was obtained at $3 \mathrm{~h}$ and then decreased (Fig. 5B). The yield of GlcN and conversion ratio in 3-L bioreactor were improved, where environmental conditions are wellcontrolled. The maximal titer of GlcN increased from 30.2 to $35.3 \mathrm{~g} / 1$, and the molar conversion ratio of GlcNAc to GlcN increased from $74.7 \%$ to $86.8 \%$ (Fig. 6).

In summary, we successfully devised a whole-cell biotransformation method for GlcN production by expressing diacetylchitobiose deacetylase from P. horikoshii in E. coli and B. subtilis. By means of the latter engineered strain as a biocatalyst, the maximal titer of GlcN was $35.3 \mathrm{~g} / 1$ after incubation of the engineered B. subtilis $(18.6 \mathrm{~g} / \mathrm{l})$ with $50 \mathrm{~g} / 1$ GlcNAc for $3 \mathrm{~h}$ at $40^{\circ} \mathrm{C}$ and $\mathrm{pH} 7.5$. The conversion ratio of GlcNAc was $86.8 \%$ under these conditions. Further improvement of the biocatalyst activity is necessary to obtain a higher titer of GlcN for industrial production of GlcN. The performance of the biocatalyst may be improved in the future by modifying the catalytic domain of Dac $\mathrm{ph}_{\mathrm{ph}}$. As for substrate binding and product inhibition, it is possible to create highly active and product-noninhibited enzyme mutants by genetic and protein engineering. Moreover, bio-based production provides attractive alternatives to overcome drawbacks in the process of chemical synthesis, like unstable intermediates, multistep reactions, and complex process control, to name a few, it is worthwhile to develop such an environmentally friendly bio-based approach for industrial production of GlcN.

\section{Acknowledgments}

This work was financially supported by the National Outstanding Youth Foundation (31622001), 863 Program (2014AA021200, 2014AA021201), 111 project (111-2-06) and the China Postdoctoral Science Foundation (2018M630523).

\section{Conflict of Interest}

The authors have no financial conflicts of interest to declare.

\section{References}

1. Chen JK, Shen CR, Liu CL. 2010. N-acetylglucosamine: production and applications. Marine Drugs 8: 2493-2516.

2. Nakamura H. 2011. Application of glucosamine on human disease-Osteoarthritis. Carbohydr. Polym. 84: 835-839.

3. Hungerford DS, Jones LC. 2003. Glucosamine and chondroitin sulfate are effective in the management of osteoarthritis. $J$. Arthroplasty. 18: 5-9.

4. Towheed TE. 2003. Current status of glucosamine therapy in osteoarthritis. Arthritis Rheum. 49: 601-604.

5. Sitanggang AB, Wu HS, Wang SS, Ho YC. 2010. Effect of pellet size and stimulating factor on the glucosamine production using Aspergillus sp. BCRC 31742. Bioresour. Technol. 101: 3595-3601.

6. Zhang J, Liu L, Li J, Du G, Chen J. 2012. Enhanced glucosamine production by Aspergillus sp. BCRC 31742 based on the time-variant kinetics analysis of dissolved oxygen level. Bioresour. Technol. 111: 507-511.

7. Chen X, Liu L, Li J, Du G, Chen J. 2012. Improved glucosamine and $\mathrm{N}$-acetylglucosamine production by an engineered Escherichia coli via step-wise regulation of dissolved oxygen level. Bioresour. Technol. 110: 534-538.

8. Deng MD, Severson DK, Grund AD, Wassink SL, Burlingame RP, Berry A, et al. 2005. Metabolic engineering of Escherichia coli for industrial production of glucosamine and $\mathrm{N}$-acetylglucosamine. Metab. Eng. 7: 201-214.

9. Liu Y, Liu L, Shin HD, Chen RR, Li J, Du G, et al. 2013. Pathway engineering of Bacillus subtilis for microbial production of N-acetylglucosamine. Metab. Eng. 19: 107-115.

10. Mine S, Ikegami T, Kawasaki K, Nakamura T, Uegaki K. 2012. Expression, refolding, and purification of active diacetylchitobiose deacetylase from Pyrococcus horikoshii. Protein Expr. Purif. 84: 265-269. 
11. Kang Z, Yang S, Du G, Chen J. 2014. Molecular engineering of secretory machinery components for high-level secretion of proteins in Bacillus species. J. Ind. Microbiol. Biotechnol. 41: 1599-1607.

12. Tanaka T, Fukui T, Fujiwara S, Atomi H, Imanaka T. 2004. Concerted action of diacetylchitobiose deacetylase and exobeta-D-glucosaminidase in a novel chitinolytic pathway in the hyperthermophilic archaeon Thermococcus kodakaraensis KOD1. J. Biol. Chem. 279: 30021-30027.

13. Mine S, Niiyama M, Hashimoto W, Ikegami T, Koma D, Ohmoto T, et al. 2014. Expression from engineered Escherichia coli chromosome and crystallographic study of archaeal N,N'-diacetylchitobiose deacetylase. FEBS J. 281: 2584-2596.

14. Nicolas P, Mader U, Dervyn E, Rochat T, Leduc A, Pigeonneau N, et al. 2012. Condition-dependent transcriptome reveals high-level regulatory architecture in Bacillus subtilis. Science 335: 1103-1106.

15. Promchai R, Promdonkoy B, Tanapongpipat S, Visessanguan W, Eurwilaichitr L, Luxananil P. 2016. A novel salt-inducible vector for efficient expression and secretion of heterologous proteins in Bacillus subtilis. J. Biotechnol. 222: 86-93.

16. Bertram R, Rigali S, Wood N, Lulko AT, Kuipers OP, Titgemeyer F. 2011. Regulon of the $N$-acetylglucosamine utilization regulator NagR in Bacillus subtilis. J. Bacteriol. 193: 3525-3536.

17. Vincent F, Yates D, Garman E, Davies GJ, Brannigan JA. 2004. The three-dimensional structure of the $\mathrm{N}$-acetylglucosamine- 6-phosphate deacetylase, NagA, from Bacillus subtilis: a member of the urease superfamily. J. Biol. Chem. 279: 28092816.

18. Song Y, Li J, Shin HD, Du G, Liu L, Chen J. 2015. One-step biosynthesis of alpha-ketoisocaproate from L-leucine by an Escherichia coli whole-cell biocatalyst expressing an L-amino acid deaminase from Proteus vulgaris. Sci. Rep. 5: 12614.

19. Westers L, Westers H, Quax WJ. 2004. Bacillus subtilis as cell factory for pharmaceutical proteins: a biotechnological approach to optimize the host organism. Biochim. Biophys. Acta 1694: 299-310.

20. Zhang XZ, Cui ZL, Hong Q, Li SP. 2005. High-level expression and secretion of methyl parathion hydrolase in Bacillus subtilis WB800. Appl. Environ. Microbiol. 71: 4101-4103.

21. Mine S, Ikegami T, Kawasaki K, Nakamura T, Uegaki K. 2012. Expression, refolding, and purification of active diacetylchitobiose deacetylase from Pyrococcus horikoshii. Protein Express. Purification 84: 265-269.

22. Shi F, Li K, Huan X, Wang X. 2013. Expression of NAD(H) kinase and glucose-6-phosphate dehydrogenase improve $\mathrm{NADPH}$ supply and L-isoleucine biosynthesis in Corynebacterium glutamicum ssp. lactofermentum. Appl. Biochem. Biotechnol. 171: 504-521.

23. Blombach B, Schreiner ME, Holatko J, Bartek T, Oldiges M, Eikmanns BJ. 2007. L-valine production with pyruvate dehydrogenase complex-deficient Corynebacterium glutamicum. Appl. Environ. Microbiol. 73: 2079-2084. 